Morris, P.J. Chupas, L. Monconduit, C.P. Grey, J. Am. Chem. Soc. (2016) 138, 2352

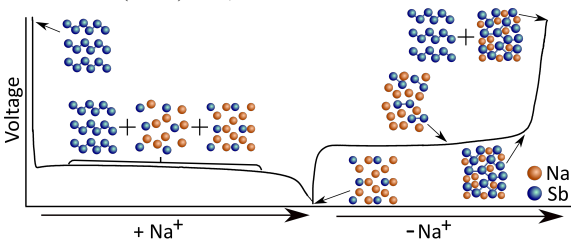

Figure 1. Schematic of the sodiation processes in antimony anodes

Keywords: pair distribution function analysis, batteries, in operando

\section{MS19-03 Quasi-Elastic Neutron Scattering} Studies on Solid Electrolytes for all-solid-state Lithium Batteries

Didier Blanchard ${ }^{1}$, Jon Steinar G. Myrdal ${ }^{1}$, Dadi Sveinbjornsson ${ }^{1}$, Peter NGene ${ }^{2}$, Petra de Jongh ${ }^{2}$, Tejs Vegge ${ }^{1}$

1. Department of Energy, Technical University of Denmark (DTU), Denmark

2. Inorganic Chemistry and Catalysis, Debye Institute for Nanomaterials Science, Utrecht University, The Netherlands

email: dibl@dtu.dk

The development of better batteries is paramount for market penetration of electrical vehicle and integration of renewable energy sources into the grid. For today's best technology, state-of-the-art lithium-ion battery, limited improvement in capacity and cost are expected because of the use of organic liquid or gel electrolytes limiting the choice of electrode materials and exposing to safety concerns. A choice alternative is to use solid electrolytes instead.

The high temperature phase of lithium borohydride $\left(\mathrm{LiBH}_{4}\right)$, hexagonal crystal structure at temperature above $383 \mathrm{~K}$, is a fast $\mathrm{Li}+$ conductor $\left(\sigma \sim 10^{-4} \mathrm{~W}^{-1} \cdot \mathrm{cm}^{-1}\right) .^{[1]}$ This property is kept at room temperature by stabilizing the hexagonal phase with $\mathrm{Li}$ halides ${ }^{[2]}$ or confining $\mathrm{LiBH}_{4}$ in nanoporous scaffolds. ${ }^{[3]}$

We have studied the $\mathrm{Li}^{+}$diffusion in $\mathrm{LiBH}$ with Density Functional Theory (DFT) coupled to Quasi-Elastic Neutron Scattering (QENS). DFT shows that lithium defects such as Frenkel pairs are easily formed at room temperature $\left(\mathrm{E}_{\mathrm{f}}=0.44 \mathrm{eV}\right)$ and low energy barriers $(0.3 \mathrm{eV})$ are found between stable defect sites, giving rise to high defect mobility (Fig.1-a). The most favorable mechanism for the $\mathrm{Li}^{+}$conduction is calculated to occur in the hexagonal plane. The QENS results at $380 \mathrm{~K}$ show long range diffusion of $\mathrm{Li}^{+}$, with jump lengths of one unit cell in the hexagonal plane and rates in agreement with DFT. At $300 \mathrm{~K}$, QENS reveals jumps of shorter length $(\sim 2 \AA)$, which could correspond to jump of $\mathrm{Li}^{+}$interstitials to intermediate lattice sites, in agreement with DFT. ${ }^{[4]}$

QENS was also used to probe the dynamic of the $\mathrm{BH}_{4}^{-}$ anions in $\mathrm{LiBH}_{4}$ confined in nanoporous $\mathrm{SiO}_{2}$. Four quasi-elastic components were found in two different temperature domains. At low temperature, $<170 \mathrm{~K}$, the components are an order of magnitude broader than those at high temperature, however still below the phase transition (Fig.1-b). The narrower components are associated with reorienting $\mathrm{BH}_{4}^{-}$anions in crystalline $\mathrm{LiBH}_{4}$, while the broader components, with much more rapidly reorienting $\mathrm{BH}_{4}^{-}$, can be associated with the fraction of $\mathrm{LiBH}_{4}$ located at the $\mathrm{SiO}_{2}$ surfaces, reflecting a disruption of the bulk crystal lattice. It suggests that the high $\mathrm{Li}^{+}$conductivity takes place at the interface between $\mathrm{LiBH}_{4}$ and $\mathrm{SiO}_{2}$.

[1] Matsuo et al., Appl. Phys. Lett. 2007, 91, 224103.

[2] Sveinbjörnsson et al., J. Phys. Chem. C 2013, 117, 3249 .

[3] Blanchard et al., Adv. Funct. Mater. 2014, 1.

[4] Myrdal et al., J. Phys. Chem. C 2013, 117, 9084. 

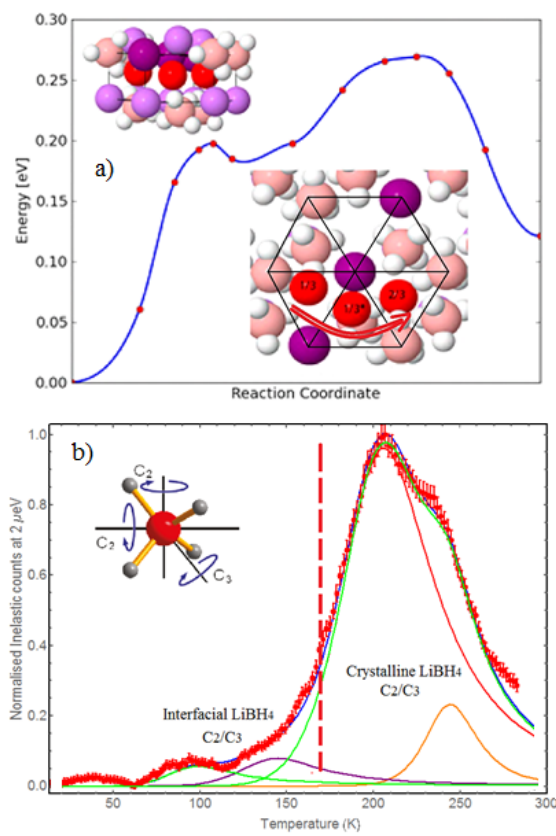

Figure 1. a) DFT energy path for interstitial Li diffusion. b) $\mathrm{LiBH}_{4} / \mathrm{SiO}_{2}$ neutron inelastic temperature scans. The four quasi-elastic components correspond to reorientational diffusion of the $\mathrm{BH}_{4}{ }^{-}$along the $\mathrm{C}_{2}-\mathrm{C}_{3}$ axis for the interfacial $\mathrm{LiBH}_{4}$ (low temp.) and crystalline $\mathrm{LiBH}_{4}^{3}$ ( high temp.).

Keywords: Battery, Quasi-elastic Neutron Scattering, Density Functional Theory, all-solid-sate battery, solid electrolyte

\section{MS19-04 Characterization of cation ordering, oxygen vacancy distribution and proton sites in hexagonal and cubic$$
\mathrm{BaTi}_{1-\mathrm{x}} \mathrm{Sc}_{\mathrm{x}} \mathrm{O}_{3-\delta}
$$

Paul F. Henry ${ }^{1,2}$, Nico Torino ${ }^{2}$, Habibur S.M. Rahman ${ }^{2}$, Christopher S. Knee ${ }^{2}$, Sten G. Eriksson ${ }^{2}$, Stefan T. Norberg ${ }^{2}$, Tor S. Bjørheim ${ }^{3}$, Reidar Haugsrud ${ }^{3}$, Sam Callear ${ }^{4}$, Ron Smith ${ }^{4}$

1. European Spallation Source ERIC, Lund, Sweden

2. Chalmers University of Technology, Gothenburg, Sweden

3. University of Oslo, Norway

4. STFC, Didcot, UK

email: paul.henry@esss.se

Proton conducting oxides find applications as electrolyte materials in fuel cells, steam electrolysers and hydrogen and humidity sensors. Proton conducting fuel cells, which use $\mathrm{H}_{2}$ as a fuel, stand out as a promising technology for future clean energy generation. However, its success relies on the discovery of novel electrolyte materials with high protonic conduction at intermediate temperatures $\left(200-600^{\circ} \mathrm{C}\right)$. Acceptor doped perovskites are actively studied in the search for improved proton conducting materials. We have synthesized and characterized the proton conducting properties of the series $\mathrm{BaTi}_{1-\mathrm{x}} \mathrm{Sc}_{\mathrm{x}} \mathrm{O}_{3-\delta}(0.1 \leq \mathrm{x} \leq 0.8)$. [1,2] The series shows a transition from a $6 \mathrm{H}$ perovskite structure at low scandium doping to a cubic phase for $x \geq 0.5$. All the doped series show hydration behavior indicative of filling oxide ion vacancies within the structure and that protons are the dominant charge carriers below $600{ }^{\circ} \mathrm{C}$. The conductivity of the materials with the $6 \mathrm{H}$ structure is significantly lower than those with the cubic structure. $\mathrm{X}$-ray data suggest different oxygen vacancy ordering within the $6 \mathrm{H}$ perovskite structure at low doping levels, whereas the vacancies are distributed randomly in the cubic structure with no evidence of long range ordering of the $\mathrm{Ti}$ and $\mathrm{Sc}$ ions on the B-site. However, due to the weak scattering from oxygen $c f$. the transition metals and barium, coupled with the similar scattering power of the $\mathrm{Ti}$ and $\mathrm{Sc}$, the presence of cation and/or oxygen ion order and the driving force for the phase transition to the cubic structure are unknown. Moreover, the origin of the poorer conductivity of the $6 \mathrm{H} c f$. the cubic structure upon hydration is also unknown and is likely related to the proton sites and the exchange pathways within the material. Neutron powder diffraction (NPD) and recent in situ studies using combined NPD/thermogravimetric analysis resolving these key questions will be presented and coupled to DFT calculations.

[1] S.M.H Rahman, I. Ahmed, R. Haugsrud, S.G. Eriksson, C.S. Knee. (2014) Solid State Ionics, 255 , 140-146.

[2] S.M.H. Rahman, S.T. Norberg, C.S. Knee, J.J. Biendicho, S. Hull, S.G. Eriksson, (2014) Dalton Transactions, 43, 15055.

Keywords: neutron, powder diffraction, structure 